\title{
Production and Tolerance of Ethanol in Relation to Phospholipid Fatty-acyl Composition in Saccharomyces cerevisiae NCYC 431
}

\author{
By MICHAEL J. BEAVEN, CLAUDINE CHARPENTIER† AND \\ ANTHONY H. ROSE* \\ Zymology Laboratory, School of Biological Sciences, Bath University, Bath, Avon, U.K.
}

(Received 26 August 1981; revised 28 October 1981)

\begin{abstract}
Accumulation of ethanol in supernatants from anaerobic cultures of Saccharomyces cerevisiae NCYC 431 closely paralleled growth during the early exponential phase of batch growth, and continued after growth had ceased. During the 8-64h period of the fermentation, the intracellular ethanol concentration was greater than the extracellular concentration. Ethanol was very rapidly extracted from organisms by washing with water. During growth up to $32 \mathrm{~h}$, there was a progressive decrease in fatty-acyl unsaturation in phospholipids, and a corresponding proportional increase in saturation. Thereafter, the trend was very slightly reversed. Supplementing cultures with ethanol $(0.5$ or $1.0 \mathrm{M})$ after $8 \mathrm{~h}$ incubation retarded growth rate, while supplementation with $1.5 \mathrm{M}$-ethanol immediately stopped growth. In cultures supplemented with 0.5 or $1.0 \mathrm{M}$-ethanol, viability was not lowered, but supplementation with $1.5 \mathrm{M}$-ethanol caused a rapid decline in viability. Supplementation of cultures with ethanol at any of the three concentrations led to an increase in the proportion of mono-unsaturated fatty-acyl residues in cellular phospholipids, especially in $\mathrm{C}_{18}$ residues, which was accompanied by a decrease in the proportion of saturated residues.
\end{abstract}

\section{INTRODUCTION}

Although it has been established for well over a century that strains of Saccharomyces cerevisiae, when grown under anaerobic conditions, convert a large proportion of the glucose supplied into ethanol and carbon dioxide (Pasteur, 1879), much remains to be discovered concerning this energy-generating process. Recent research has concentrated on enzymes that catalyse reactions on the glycolytic pathway, and the manner in which ethanol affects the physiology of this yeast. It is known that $S$. cerevisiae synthesizes two or more isomers of several of the enzymes that catalyse reactions on the Embden-Meyerhof-Parnas pathway (Fraenkel, 1981). Moreover, several reports indicate that the enzymes may be membranebound (Rothstein et al., 1959; Green et al., 1965; Atkinson, 1969; Sols \& Marco, 1970), although it has yet to be demonstrated that they exist in a multi-enzyme complex as in Escherichia coli (Mowbray \& Moses, 1976).

While ethanol is well known to be capable of denaturing proteins (Cohn et al., 1950), some strains of $S$. cerevisiae are recognized as being among the most ethanol-tolerant of micro-organisms. However, little is known of the physiological basis for this tolerance (Rose, 1980). Ethanol has been reported to inhibit the activity of hexokinase and $\alpha$-glycerophosphate dehydrogenase, but not phosphofructokinase, in extracts of $S$. cerevisiae (Augustin et al., 1965; Nagodawithana et al., 1977), although it is presumed that the inhibitory effects are less extensive than with enzymes from other micro-organisms. Work in this laboratory has focused on the importance of cell lipids in ethanol tolerance of $S$.

\footnotetext{
† Permanent address: École Nationale Supérieure de Biologie Appliquée à la Nutrition et à l'Alimentation, Université de Dijon, Dijon, France.
} 
cerevisiae. Loss of viability in ethanol-containing buffered suspensions of $S$. cerevisiae NCYC 366 was less rapid when the organisms contained plasma membranes enriched in linoleyl rather than oleyl residues, or enriched in ergosterol or stigmasterol rather than campesterol or cholesterol (Thomas et al., 1978). The same strain of $S$. cerevisiae was also more sensitive to inhibition of growth by ethanol when the plasma membrane was enriched in oleyl as compared with linoleyl residues, while transport systems for several solutes were inhibited to a greater extent when membranes containing the mono-unsaturated as compared with di-unsaturated residues (Thomas \& Rose, 1979).

The present paper reports on the time-course of accumulation of intracellular and extracellular ethanol in batch cultures of $S$. cerevisiae NCYC 431, on the effect of adding ethanol to these cultures, and on changes in the lipid composition of exponentially-growing organisms exposed to additional ethanol.

\section{METHODS}

Organism. The yeast used in this study was $S$. cerevisiae NCYC 431, a strain isolated originally from a distillery. It was maintained on slopes of malt extract/yeast extract/glucose/mycological peptone (MYGP) medium (Wickerham, 1951) solidified with $2 \%(\mathrm{w} / \mathrm{v})$ agar.

Experimental cultures. Cultures (1 litre) were grown in 2-litre round flat-bottomed flasks fitted with a fermentation lock as described by Alterthum \& Rose (1973), except that they were not sparged with nitrogen gas, and were maintained in a constant temperature $\left(30^{\circ} \mathrm{C}\right)$ room and stirred on a flat-bed stirrer $\left(50 \mathrm{rev}\right.$. $\left.\mathrm{min}^{-1}\right)$. The medium contained (per litre): glucose $200 \mathrm{~g},\left(\mathrm{NH}_{4}\right)_{2} \mathrm{SO}_{4} 3 \mathrm{~g}, \mathrm{KH}_{2} \mathrm{PO}_{4} 3 \mathrm{~g}, \mathrm{CaCl}_{2} .2 \mathrm{H}_{2} \mathrm{O} 0.25 \mathrm{~g}, \mathrm{MgSO}_{4} \cdot 7 \mathrm{H}_{2} \mathrm{O}$ $0.25 \mathrm{~g}$, and yeast extract (Lab M; London Analytical and Bacteriological Media, London) $4 \mathrm{~g}$. After adjustment to pH 4.5 with $\mathrm{HCl}$, batches were sterilized at $10 \mathrm{lbf} \mathrm{in}^{-2}(68.9 \mathrm{kPa})$. Starter cultures $(100 \mathrm{ml}$ of the same medium in a $250 \mathrm{ml}$ conical flask) were inoculated from slope cultures of the yeast and incubated at $30^{\circ} \mathrm{C}$ on a Gallenkamp shaker incubator ( $250 \mathrm{rev} \cdot \mathrm{min}^{-1}$ ) for $16 \mathrm{~h}$. A portion of starter culture, containing $10 \mathrm{mg}$ dry wt equiv., was added to 1 litre of medium. Growth was followed by removing portions of culture through a Suba seal on the side of the flask and measuring the $A_{1 \mathrm{~cm}, 600}$ value of the sample after appropriate dilution if necessary. Absorbance readings were related to dry wt equiv. of organism, values for which were determined by filtering a portion of culture on to preweighed filters (Millipore; $0.45 \mu \mathrm{m}$ pore size; $25 \mathrm{~mm}$ diam.), washing with water and drying at $105^{\circ} \mathrm{C}$ for $24 \mathrm{~h}$. Organisms were harvested at the stages indicated by centrifuging cultures in an MSE High Speed 18 centrifuge at $4^{\circ} \mathrm{C}$ for $1 \mathrm{~min}$ at $13000 \mathrm{~g}$.

Ethanol determinations. The following method was developed for estimation of intracellular and extracellular ethanol. After organisms were harvested by centrifugation, the supernatant liquid was removed and a portion retained for determination of extracellular ethanol. The organisms were then resuspended in cold $\left(4^{\circ} \mathrm{C}\right)$ culture supernatant to $10 \mathrm{mg}$ dry wt ml-1. A portion $(10 \mathrm{ml})$ of the suspension was centrifuged at $27000 \mathrm{~g}$ for $2 \mathrm{~min}$ at $4{ }^{\circ} \mathrm{C}$. The supernatant was decanted and retained for ethanol determination, the inside of the centrifuge tube was wiped dry with filter paper, and the organisms were suspended in $10 \mathrm{ml}$ water. The suspension was added to $35 \mathrm{~g}$ glass beads (Glasperlen; B. Braun, Melsungen, F.R.G.; $0.45-0.50 \mathrm{~mm}$ diam.) and shaken for two periods of $30 \mathrm{~s}$ in a Braun homogenizer at speed $2\left(4000 \mathrm{rev} . \mathrm{min}^{-1}\right)$. The suspension of disrupted organisms was centrifuged, and a portion of the supernatant liquid removed for ethanol determination.

In order to calculate the concentration of ethanol inside the plasma membrane of organisms, it was necessary to know the volume accounted for in packed organisms by interstitial water and wall water, and the total volume which equilibrates with water. These values were determined by suspending organisms in a solution containing ${ }^{3} \mathrm{H}_{2} \mathrm{O}$, which equilibrates with both extracellular and intracellular water, and ${ }^{36} \mathrm{Cl}^{-}$, which equilibrates with interstitial water and water in the wall but does not penetrate the plasma membrane. Keenan (1981, and unpublished observations) confirmed the claim by Rothstein (1972) that chloride ions are not accumulated by $S$. cerevisiae. Buffered suspensions of organisms containing $0.001,1.0$ or $100 \mathrm{mM}-\mathrm{NaCl}$, including $\mathrm{Na}^{36} \mathrm{Cl}$, were unable to accumulate chloride ions when incubated at $30^{\circ} \mathrm{C}$ for up to $60 \mathrm{~min}$. A very small amount of radioactivity was retained by organisms, representing approximately $0.001 \%$ of the radioactivity included in the range $1 \cdot 24-2 \cdot 10$ c.p.m. (mg dry wt) ${ }^{-1}$. This radioactivity could not be removed from organisms by washing with $\mathrm{NaCl}$, and was attributed to a low level of contamination of the $\mathrm{Na}^{36} \mathrm{Cl}$ with some other radioactive compound.

Portions of culture were rapidly cooled by passing down a spiral glass column surrounded by antifreeze $(40 \%$, $\mathrm{v} / \mathrm{v}$, ethylene glycol at $-5^{\circ} \mathrm{C}$ ) and organisms harvested by centrifugation $(13000 \mathrm{~g}$ for $1 \mathrm{~min})$. All subsequent steps were carried out at $4{ }^{\circ} \mathrm{C}$; tubes were flushed with high-purity nitrogen gas before use and at convenient times throughout the procedure. Organisms were washed twice with cold $\left(4^{\circ} \mathrm{C}\right)$ water and resuspended in water at $100 \mathrm{mg}$ dry wt $\mathrm{ml}^{-1}$. A portion $(5 \mathrm{ml})$ of the suspension was dispensed into a tapered centrifuge tube and centrifuged at $27000 \mathrm{~g}$ for $1 \mathrm{~min}$. The supernatant liquid was decanted and the inside of the tube wiped dry with 
filter paper. The organisms were then suspended in $0.8 \mathrm{ml}$ water to which was added $0.1 \mathrm{ml}^{3} \mathrm{H}_{2} \mathrm{O}\left(1.5 \mu \mathrm{Ci} \mathrm{ml}{ }^{-1}\right.$;

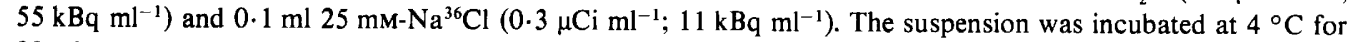
$20 \mathrm{~min}$, the contents of the tubes being inverted twice each minute. The suspension was then centrifuged at $27000 \mathrm{~g}$ for $1 \mathrm{~min}$ and portions $(0.2 \mathrm{ml})$ of the supernatant liquid were added to vials containing $7 \mathrm{ml}$ scintillation fluid (Unisolve no. 1). The radioactivity of the contents of the vials was measured using an LKB 1215 Rack Beta scintillation spectrometer.

Ethanol concentrations in culture supernatants and extracts were determined by gas-liquid chromatography. A portion $(3 \mathrm{ml})$ of supernatant or extract was diluted as necessary with water; from this, a portion $(0.5 \mathrm{ml})$ was mixed with an equal volume of $0.2 \%(\mathrm{v} / \mathrm{v})$ acetone in water, and $1 \mu \mathrm{l}$ of the solution was injected on to the column of a Pye GCD gas chromatograph fitted with a flame ionization detector (oven temperature $300{ }^{\circ} \mathrm{C}$ ). The column $(1.5 \mathrm{~m}$ long, $0.4 \mathrm{~cm}$ internal diam.) was packed with Chromosorb $101(100 / 120$ mesh) and maintained at $150^{\circ} \mathrm{C}$. The injection oven temperature was $250^{\circ} \mathrm{C}$, and the nitrogen gas carrier flow rate $40 \mathrm{ml} \mathrm{min}^{-1}$. Standards containing $0.05,0.10,0.15$ and $0.20 \%(\mathrm{v} / \mathrm{v})$ ethanol were run with each batch of samples. The value for the peak height multiplied by the retention time for samples was related to ethanol concentration by a standard curve.

Lipid analysis. Before harvesting, a solution $(2 \mathrm{ml})$ containing $10 \mathrm{mg}$ each of cycloheximide and chloramphenicol was injected into the culture through the Suba-seal (Alterthum \& Rose, 1973), and the culture was incubated for a further $15 \mathrm{~min}$. After harvesting, organisms were washed twice with water, and lipid was extracted by a modification of the procedure of Folch et al. (1957). Washed organisms (500 mg dry wt) were mixed with methanol $(10 \mathrm{ml})$ and the suspension was shaken in a Braun homogenizer for two periods of $30 \mathrm{~s}$ at speed 2 (4000 rev. $\min ^{-1}$ ) after addition of $35 \mathrm{~g}$ glass beads (Sigma type V; 0.45-0.50 mm diam.). Chloroform was then added to the suspension to give the ratio $2: 1(\mathrm{v} / \mathrm{v})$ chloroform/methanol, and the suspension was stirred on a flatbed stirrer for $2 \mathrm{~h}$ at room temperature $\left(20-22^{\circ} \mathrm{C}\right)$. The suspension was then filtered through Whatman no. 44 filter paper, and the extraction procedure was repeated on the residue. The combined extracts were washed with 0.25 vol. $0.88 \%(\mathrm{w} / \mathrm{v}) \mathrm{KCl}$ and the mixture was separated by centrifugation or left to separate overnight at $4{ }^{\circ} \mathrm{C}$. The lower phase was removed and taken to dryness on a rotary evaporator; the residue was immediately dissolved in chloroform/methanol $(2: 1, \mathrm{v} / \mathrm{v})$. Samples were stored under nitrogen gas at $-20^{\circ} \mathrm{C}$. The phospholipid fraction was separated from other lipid classes in extracts by thin layer chromatography on plates of silica gel $\mathrm{H}(0.5 \mathrm{~mm}$ thick) using a solvent system of hexane/diethyl ether/glacial acetic acid (70:30:2, by vol.). Lipid bands were located by exposing plates to iodine vapour, and were marked with a pin. The phospholipid band was identified by reference to simultaneously run standards of phosphatidylcholine or phosphatidylethanolamine. The iodine was allowed to sublime at room temperature, the phospholipid band was scraped off the plates, and fatty acid methyl esters were prepared by refluxing the silica gel with methanol containing $14 \%(\mathrm{w} / \mathrm{v}) \mathrm{BF}_{3}$ for $10 \mathrm{~min}$. After cooling, an equal volume of water was added, and the methyl esters were extracted into chloroform. Fatty-acid methyl esters were analysed by gas-liquid chromatography on a column ( $2 \mathrm{~m}$ ) of $15 \%$ EGSS-Y supported on $100 / 120$ mesh Gas-Chrom $\mathrm{P}$ at $175^{\circ} \mathrm{C}$. The injection port was at $210^{\circ} \mathrm{C}$, and the carrier gas $\left(\mathrm{N}_{2}\right)$ flow rate was $40 \mathrm{ml} \mathrm{min}^{-1}$. Percentage fatty-acid compositions were calculated by multiplying the retention time by the peak height on the trace.

Viability measurements. Viability of populations was measured by an adaptation of the slide-culture technique (Postgate, 1969) and by staining with methylene blue. Organisms harvested from portions of culture by centrifugation were washed once with MYGP medium which had been filtered through a glass fibre filter (Whatman GF/F; $4.7 \mathrm{~cm}$ diam; $0.45 \mu \mathrm{m}$ pore size), and suspended in the same medium to a concentration of $0.1 \mathrm{mg}$ dry $\mathrm{wt} \mathrm{m}^{-1}$. The suspension was subjected to ultrasound for $20 \mathrm{~s}$ using an MSE $100 \mathrm{~W}$ ultrasonicator fitted with a $3 \mathrm{~mm}$ probe on drive setting 7. A loopful of the sonicated suspension was spread over a block $(2 \mathrm{~cm}$ diam; $0.2 \mathrm{~cm}$ thick) of MYGP medium solidified with $2 \%(\mathrm{w} / \mathrm{v})$ agar and contained in a Petri dish. The lid was lined with damp filter paper, and the dish incubated upside down for $7 \mathrm{~h}$ at $30^{\circ} \mathrm{C}$ or $16 \mathrm{~h}$ at $20^{\circ} \mathrm{C}$. The surface of the block was then examined with a phase-contrast microscope, and microcolonies and single organisms were counted in five fields, each of which contained about 60 objects. Viability is expressed as the ratio of the number of microcolonies to the total number of objects. Staining with methylene blue (Fink \& Kühles, 1933) was used to obtain a rapid assessment of the viability of cultures. A portion $(1.0 \mathrm{ml})$ of culture diluted to $0.5 \mathrm{mg}$ dry wt $\mathrm{ml}^{-1}$ was stained with methylene blue solution $(0.01 \%, \mathrm{w} / \mathrm{v}$; containing $2 \%$, w/v, trisodium citrate) for $10 \mathrm{~min} ; 1000$ organisms were scored for uptake of the dye.

Chemicals. All chemicals used were of Analar grade or of the highest purity available commercially. Radioactively labelled chemicals were purchased from Amersham.

\section{RESULTS}

Time-course of ethanol production in cultures

Accumulation of extracellular ethanol closely paralleled growth during the early exponential phase of growth; thereafter the rate of accumulation was slower, but excretion 


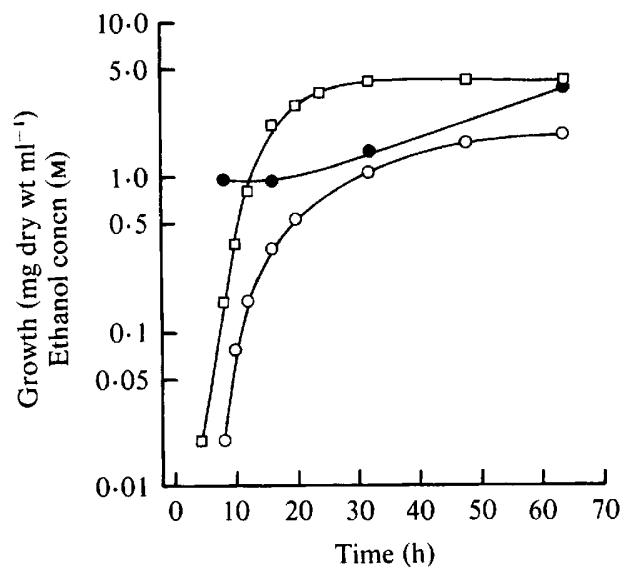

Fig. 1. Time-course of growth $(\square)$ of, and accumulation of intracellular (O) and extracellular (O) ethanol in, cultures of Saccharomyces cerevisiae NCYC 431. Each value is the mean of three independent determinations.

Table 1. Contents of interstitial and wall-bound water and of intracellular water during growth of Saccharomyces cerevisiae NCYC 431

Values quoted are the means of two determinations.

Age of
culture

(h)

8

16

32

64
Density of culture
(mg dry wt $\left.\mathrm{ml}^{-1}\right)$

0.17

$2 \cdot 05$

$4 \cdot 20$

4.00
Interstitial and

wall-bound water

$\left[\mu \mathrm{l}(\mathrm{mg} \text { dry } \mathrm{wt})^{-1}\right]$

$$
\begin{aligned}
& 2.35 \\
& 1.24 \\
& 1.00 \\
& 0.96
\end{aligned}
$$

Intracellular water [ $\mu \mathrm{l}(\mathrm{mg} \text { dry } w t)^{-1}$ ]
1.93
$1 \cdot 61$
$1 \cdot 57$
1.01

Table 2. Leakage of ethanol from Saccharomyces cerevisiae NCYC 431 during washing with water

Organisms were from cultures containing $2.4 \mathrm{mg}$ dry wt $\mathrm{ml}^{-1}$. The extracellular concentration of ethanol was $20 \mu \mathrm{g}^{-1}(0.43 \mathrm{M})$ and the intracellular concentration $49 \mu \mathrm{g} \mu \mathrm{l}^{-1}(1.06 \mathrm{M})$. A population (110 mg dry wt) was separated by centrifugation, and submitted to five consecutive washings with $10 \mathrm{ml}$ water at room temperature. The ethanol contents of all washes were adjusted to account for release of interstitial and wall-bound ethanol. After the fifth washing, the organisms were disrupted by shaking with glass beads. Ethanol was not detectable in the suspension of disrupted organisms. Values quoted are the means of two determinations on each of two batches of organisms.

Release of intracellular ethanol

Wash no. [ $\left.\mu \mathrm{g}(\mathrm{mg} \text { dry wt) })^{-1}\right]$

$$
\begin{gathered}
76 \cdot 60 \\
2.64 \\
0.36 \\
\text { ND } \\
\text { ND }
\end{gathered}
$$

\section{Percentage of intracellular} ethanol released

$96 \cdot 2$

0.5

ND, Ethanol not detectable. 
Table 3. Changes in the fatty-acyl composition of phospholipids of Saccharomyces cerevisiae NCYC 431 during growth

Values quoted are the means of the two determinations made on organisms from separate cultures. Values for unsaturation $\left(\Delta \mathrm{mol}^{-1}\right)$ were calculated as described by Kates \& Hagen (1964).

\begin{tabular}{lcccc} 
& \multicolumn{4}{c}{ Age of culture $(\mathrm{h})$} \\
\cline { 2 - 4 } & 8 & 16 & 32 & 64 \\
Density of organisms (mg dry wt $\left.\mathrm{ml}^{-1}\right)$ & 0.17 & 2.1 & 4.2 & 4.0 \\
Fatty-acyl residue (\% of total): & & & & \\
$\mathrm{C}_{14: 0}$ & 1.5 & 1.7 & 1.1 & 0.6 \\
$C_{14: 1}$ & 0.5 & 0.5 & 0.6 & 1.0 \\
$C_{16: 0}$ & $24 \cdot 1$ & 39.0 & 46.1 & 41.7 \\
$C_{16: 1}$ & 43.6 & 32.8 & 25.8 & 26.9 \\
$C_{18: 0}$ & 4.3 & 9.1 & 12.3 & 13.2 \\
$C_{18: 1}$ & 25.8 & 16.6 & 14.8 & 16.5 \\
Unsaturation $\left(\Delta \mathrm{mol}^{-1}\right)$ & 0.70 & 0.50 & 0.41 & 0.44
\end{tabular}

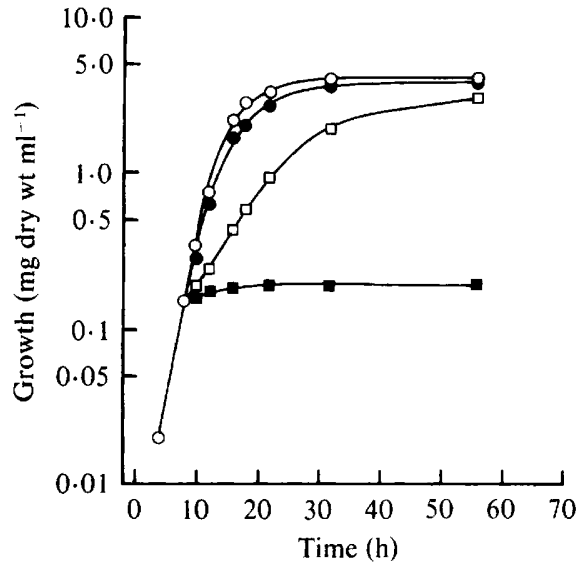

Fig. 2

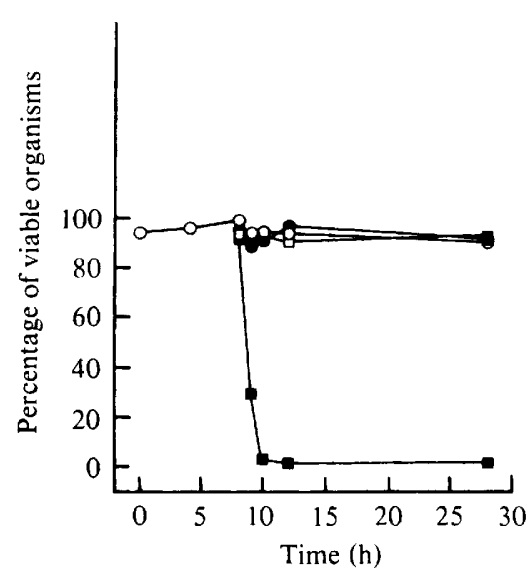

Fig. 3

Fig. 2. Effect of adding ethanol on growth of cultures of Saccharomyces cerevisiae NCYC 431. Cultures were supplemented with ethanol at $0.5 \mathrm{M}(O), 1.0 \mathrm{M}(\square)$ or $1.5 \mathrm{M}(\square)$ after $8 \mathrm{~h}$ incubation. Control cultures $(O)$ were supplemented at $8 \mathrm{~h}$ with water $(90 \mathrm{ml})$. Each value is the mean of two independent determinations.

Fig. 3. Viability of cultures of Saccharomyces cerevisiae NCYC 431 following addition, after $8 \mathrm{~h}$ incubation, of ethanol at $0.5 \mathrm{M}(\mathrm{O}), 1.0 \mathrm{M}(\square)$ or $1.5 \mathrm{M}(\square)$. Control cultures (O) were supplemented at $8 \mathrm{~h}$ with water $(90 \mathrm{ml})$. Viability was measured by a modified slide-culture technique (see Methods). Each value is the mean of two independent determinations.

continued after growth had ceased (Fig. 1). Viability was $90-95 \%$ in cultures incubated for up to $64 \mathrm{~h}$. Further incubation was accompanied by a decline in viability. The intracellular concentration of ethanol was higher than the concentration in culture supernatants throughout growth of cultures. It was almost constant during the exponential phase of growth, but steadily increased after growth had ceased. The contents of interstitial and wall-bound water and of intracellular water in organisms harvested at different stages of growth are shown in Table 1. During determinations of intracellular ethanol in organisms from $8 \mathrm{~h}$ cultures, ethanol was released when organisms were resuspended in cold culture supernatant, and the amount released was taken into account when calculating intracellular 
Table 4. Changes in the fatty-acyl composition of phospholipids of Saccharomyces cerevisiae NCYC 431 following supplementation of cultures with ethanol

\begin{abstract}
Cultures were supplemented with ethanol or water after $8 \mathrm{~h}$ incubation, and organisms harvested from cultures after a further $10 \mathrm{~h}$ incubation. Values quoted are the means of determinations on two separate batches of organisms. Values for unsaturation $\left(\Delta \mathrm{mol}^{-1}\right)$ were calculated as described by Kates \& Hagen (1964).
\end{abstract}

$\begin{gathered}\text { Fatty-acyl } \\ \text { residue }\end{gathered}$
$\mathrm{C}_{14: 0}$
$\mathrm{C}_{14: 1}$
$\mathrm{C}_{16: 0}$
$\mathrm{C}_{16: 1}$
$\mathrm{C}_{18: 0}$
$\mathrm{C}_{18: 1}$
Unsaturation $\left(\Delta \mathrm{mol}^{-1}\right)$

Fatty-acyl composition (\% of total) of phospholipids in organisms from cultures supplemented with ethanol at:

\begin{tabular}{rrrr}
\hline $0 \mathrm{M}$ & $0.5 \mathrm{M}$ & $1.0 \mathrm{M}$ & $1.5 \mathrm{M}$ \\
1.7 & 1.5 & 0.4 & 1.0 \\
0.4 & 0.3 & 0.2 & 0.4 \\
42.4 & 39.0 & 28.8 & 21.3 \\
29.1 & 27.9 & 33.5 & 37.1 \\
9.9 & 11.8 & 13.4 & 6.9 \\
16.7 & 19.6 & 23.7 & 33.5 \\
0.46 & 0.48 & 0.57 & 0.71
\end{tabular}

ethanol concentration. This release did not occur with organisms from $16 \mathrm{~h}, 32 \mathrm{~h}$ and $64 \mathrm{~h}$ cultures. The ease with which ethanol escaped from organisms during water washing is shown in Table 2. Under the conditions used, the first washing of the crop of organisms extracted the bulk of the intracellular ethanol; the remainder was completely extracted with two further washings. These results indicate why a method for determining the concentration of intracellular ethanol that did not involve washing of organisms had to be developed.

There was a progressive decrease in fatty-acyl unsaturation, and a corresponding proportional increase in saturation, in phospholipids during growth up to $32 \mathrm{~h}$ (Table 3 ). Incubation for a further $32 \mathrm{~h}$ slightly reversed this trend.

\title{
Effect of adding ethanol to cultures
}

Supplementing cultures, after $8 \mathrm{~h}$ incubation, with ethanol $(0.5$ or $1.0 \mathrm{M})$ retarded growth rate to different extents, while supplementation with $1.5 \mathrm{M}$-ethanol immediately stopped growth (Fig. 2). Viabilities of cultures as measured by the adapted slide-culture technique were unaffected when the cultures were supplemented with ethanol at concentrations up to and including $1.0 \mathrm{M}$; however, adding $1.5 \mathrm{M}$-ethanol caused a rapid decline in viability (Fig. 3 ). Similar results were obtained when viability was measured by methylene blue staining. When ethanol $(0.5,1.0$ or $1.5 \mathrm{M})$ was added to cultures after $8 \mathrm{~h}$, changes were caused to the fatty-acyl composition of phospholipids extracted from organisms harvested after a further $10 \mathrm{~h}$ growth (Table 4). All three concentrations caused an increase in the proportion of mono-unsaturated residues, especially in $\mathrm{C}_{18}$ residues, accompanied by a decrease in the proportion of saturated residues.

\section{DISCUSSION}

The linear relationship between growth of organisms and extracellular appearance of ethanol during exponential growth in anaerobic cultures of $S$. cerevisiae has long been known, and is explained by the fact that ethanol is an end product of the sole energy-generating pathway in S. cerevisiae growing under these conditions (Sols et al., 1971). Our data also confirm previous reports that ethanol is excreted in anaerobic cultures of $S$. cerevisiae for a period that extends after cessation of growth (Holzberg et al., 1967). The values we report for concentrations of intracellular ethanol in $S$. cerevisiae differ, however, from those reported by other workers who have failed to recognize two major considerations when making their determinations. The first of these is that ethanol is very rapidly released 
when organisms are washed with water or buffer. Although they did not report data on the speed at which ethanol is lost from anaerobically grown $S$. cerevisiae, Navarro \& Durand (1978) recognized this possibility when they determined the concentration of ethanol in organisms by injecting a suspension of unwashed organisms directly onto a g.l.c. column. However, values reported for the intracellular concentration of ethanol in $S$. cerevisiae by Nagodawithana \& Steinkraus (1976) and Panchal \& Stewart (1980) must be viewed critically, since both of these groups of workers washed organisms with buffer before disrupting them and determining the concentration of ethanol in the extract. In order to determine the concentration of intracellular ethanol, values are required for the content of water in the organisms. Previous workers have assumed that this value is constant during batch growth of $S$. cerevisiae (Navarro \& Durand, 1978). Our data show that this is not so: a decline in the content of water per unit dry weight of organisms was observed as the fermentation proceeded, probably being attributable to accumulation of intracellular glycogen in the later stages of growth (Chester, 1963, 1964).

Under the conditions used in the present study, excretion of ethanol was always down a concentration gradient, the magnitude of the gradient being smallest around the time growth ceased. This finding conflicts with the claim by Goma et al. (1981) that, in the later stages of anaerobic growth of $S$. cerevisiae, ethanol is excreted against a concentration gradient. This conclusion must be viewed critically because of the method used by these workers to calculate concentrations of intracellular ethanol. The data reported in the present paper also negate an earlier claim from this laboratory (Rose \& Beavan, 1981) which assumed, incorrectly, that the content of free water in anaerobically growing $S$. cerevisiae remained constant during batch growth. Passage of ethanol across the yeast plasma membrane down a concentration gradient could be by free diffusion or facilitated diffusion. While there is no evidence which precludes the involvement of a protein, it is generally assumed that movement of ethanol and other alcohols across the microbial plasma membrane is by free diffusion.

Ethanol has long been known to inhibit growth of S. cerevisiae. Both Hinshelwood (1953) and Ghose \& Tyagi (1979) claimed a linear relationship between growth rate and concentration of extracellular ethanol, while Holzberg et al. (1967) observed a threshold concentration of ethanol (about $0.6 \mathrm{M}$ ) below which there was no inhibition and above which inhibition followed a linear pattern. Our data confirm neither of these claims. Growth was inhibited at a supplemented concentration below $0.6 \mathrm{M}$, and the increases in generation time, from $1.6 \mathrm{~h}$ in unsupplemented cultures to $2.0 \mathrm{~h}$ in cultures supplemented with $0.5 \mathrm{M}$-ethanol and to $5.2 \mathrm{~h}$ in those supplemented with $1.0 \mathrm{M}$-ethanol, do not support a linear relationship between growth rate and ethanol concentration. This relationship could conceivably depend on a variety of cultural factors, including medium composition.

Although previous workers (Jollow et al., 1968) have reported an increase in the proportion of saturated and a decrease in the proportion of unsaturated fatty-acyl residues in total lipids of $S$. cerevisiae during semi-anaerobic growth, our data are the first to establish the extent to which these changes occur in phospholipids of this yeast. The changes are attributable to the requirement for molecular oxygen in synthesis of coenzyme A esters of unsaturated fatty acids from esters of their saturated counterparts (Bloomfield \& Bloch, 1958). It was therefore unexpected to observe an increase in the proportion of unsaturated fatty-acyl residues in organisms grown in the presence of additional ethanol, although a similar finding has been made by Ingram (1976) with Escherichia coli. It would appear, however, that an increase in the proportion of unsaturated fatty-acyl residues in phospholipids of $S$. cerevisiae does not indicate net synthesis of additional unsaturated residues. Assuming that ethanol does not affect synthesis of unsaturated residues, a prediction can be made of the fatty-acyl composition of organisms in cultures supplemented with ethanol, by extrapolating using curves of changes in fatty-acyl unsaturation with time for organisms from unsupplemented cultures. A comparison of predicted with observed proportions of the major residues (Table 5) reveals a virtually identical $\Delta \mathrm{mol}^{-1}$ value for 


\section{Table 5. Comparison of observed and predicted values for proportions of major fatty-acyl residues in Saccharomyces cerevisiae NCYC 431 grown in the presence of ethanol}

See text for conditions used for adding ethanol to cultures, and for the method used for predicting proportions.

Fatty-acyl composition (\% of total) of phospholipids in organisms from cultures supplemented with ethanol at:

Fatty-acyl
residue

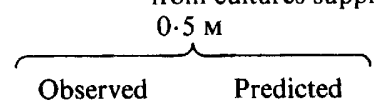

39.0

27.9

$11 \cdot 8$

19.6
38.8

$33 \cdot 2$

9.9

17.0

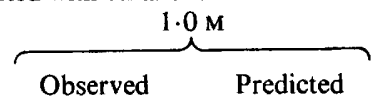

28.8

$33 \cdot 5$

13.4

$23 \cdot 7$
$33 \cdot 3$

$37 \cdot 8$

$7 \cdot 6$

$20 \cdot 0$

organisms grown in the presence of 0.5 or $1.0 \mathrm{M}$-ethanol. These data also show a difference between the observed and predicted proportions of $\mathrm{C}_{18: 0}$ residues, indicating an increased synthesis of these residues by organisms grown in the presence of $1.0 \mathrm{M}$-ethanol. A similar finding was reported by Ingram (1976) for aerobically grown $E$. coli and for Tetrahymena pyriformis by Nandini-Kishore et al. (1979). This is possibly an adaptation on the part of the organism to high concentrations of ethanol on both sides of the plasma membrane. A stress of a high concentration of an amphipathic compound on both sides of the membrane could cause the monolayers to part, and an increased synthesis of $\mathrm{C}_{18}$ fatty-acyl residues might be viewed as an adaptation to maintain membrane integrity.

\section{REFERENCES}

Alterthum, F. \& Rose, A. H. (1973). Osmotic lysis of sphaeroplasts from Saccharomyces cerevisiae grown anaerobically in media containing different unsaturated fatty acids. Journal of General Microbiology 77, 371-382.

AtKinson, D. E. (1969). Limitation of metabolite concentrations and the conservation of solvent capacity in the living cell. Current Topics in Cellular Regulation 1, 29-43.

Augustin, H. W., Kopperschläger, G., Steffen, H. \& HofmanN, E. (1965). Hexokinase als begrenzender Faktor des anaeroben Glucoseverbrauches von Saccharomyces carlsbergensis NCYC 74. Biochimica et biophysica acta 110, 437-439.

Bloomfield, D. \& Bloch, K. (1958). The role of oxygen in the biosynthesis of unsaturated fatty acids. Biochimica et biophysica acta 30, 220-221.

Chester, V. E. (1963). The dissimilation of the carbohydrate reserves of a strain of Saccharomyces cerevisiae. Biochemical Journal 86, 153-160.

Chester, V. E. (1964). Comparative studies on the dissimilation of reserve carbohydrate in four strains of Saccharomyces cerevisiae. Biochemical Journal 92, 318-323.

Cohn, E. J., Gurd, F. R. N., Surgenor, D. M., Barnes, B. A., Brown, R. K., Derouaex, G., Gillespie, J. M., KaHNT, F. W., Lever, W. F., LiU, C. H., Mittelman, D., Mouton, R. F., Schmid, K. \& Uroma, E. (1950). A system for the separation of the components of human blood: quantitative procedures for the separation of the protein compo- nents of human plasma. Journal of the American Chemical Society 72, 465-474.

FINK, H. \& KüHLES, R. (1933). Beiträge zur Methylenblaufärbung der Hefezellmembran. II. Mitteilung. Eine verbesserte Färbeflüssigkeit zur Erkennung von toten Hefezellen. Hoppe-Seyler's Zeitschrift für physiologische Chemie 218, 65-66.

Folch, J., Lees, M. \& Sloane Stanley, G. H. (1957). A simple method for the isolation and purification of total lipids from animal tissues. Journal of Biological Chemistry 226, 497-509.

FrAENKEL, D. G. (1981). The biochemical genetics of glycolysis in microbes. In Trends in the Biology of Fermentations for Fuels and Chemicals, pp. 201215. Edited by A. Hollaender, P. Rabson, P. Rogers, A. San Pietro, R. Valentine \& R. Wolfe. New York: Plenum Press.

Ghose, T. K. \& Tyagi, R. D. (1979). Rapid ethanol fermentation of cellulose hydrolysate. 1. Batch versus continuous systems. Biotechnology and Bioengineering 21, 1387-1400.

Goma, G., Moreno, M. \& Strehaiano, P. (1981). Mechanism of inhibition during alcohol fermentation in strict anaerobiosis. In Proceedings of the Symposium on Bioconversion and Bioengineering, pp. 97-112. Edited by T. K. Ghose. New Delhi: Indian Institue of Technology.

Green, D. E., Murer, E., Hultin, H. O., Richardson, S. H., Salmon, B., Brierley, G. P. \& BAUM, H. (1965). Association of integrated metabolic pathways with membranes. 1. Glycolytic 
enzymes of the red blood corpuscle and yeast. Archives of Biochemistry and Biophysics 122 , 635-647.

Hinshelwood, C. N. (1953). Autosynthesis. Journal of the Chemical Society 4, 1947-1956.

Holzberg, I., Finn, R. K. \& Steinkraus, K. H. (1967). A kinetic study of the alcoholic fermentation of grape juice. Biotechnology and Bioengineering 9, 413-427.

INGRAM, L. O. (1976). Adaptation of membrane lipids to alcohols. Journal of Bacteriology 125, 670-678.

Jollow, D., Kellerman, G. M. \& Linnane, A. W. (1968). The biogenesis of mitochondria. II. The lipid composition of aerobically and anaerobically grown Saccharomyces cerevisiae as related to the membrane systems of the cells. Journal of Cell Biology 37, 221-230.

Kates, M. \& HageN, P.-O. (1964). Influence of temperature on fatty acid composition of psychrophilic and mesophilic Serratia spp. Canadian Journal of Biochemistry 42, 481-488.

KeEnAN, M. H. J. (1981). Solute transport and plasma-membrane lipid composition in Saccharomyces cerevisiae NCYC 366. Ph.D. thesis, University of Bath, pp. 115-117.

Mowbray, J. \& Moses, V. (1976). The tentative identification in Escherichia coli of a multienzyme complex with glycolytic activity. European Journal of Biochemistry 66, 25-36.

Nagodawithana, T. W. \& Steinkraus, K. H. (1976). Influence of the rate of ethanol production and accumulation on the viability of Saccharomyces cerevisiae in 'rapid fermentation'. Applied and Environmental Microbiology 31, 158-162.

Nagodawithana, T. W., Whitt, J. T. \& Cutaia, A. J. (1977). Study of the feedback effect of ethanol on selected enzymes of the glycolytic pathway. Journal of the American Society of Brewing Chemists 35, 179-183.

Nandini-Kishore, S. G., Mattox, S. M., Martin, C. E. \& Thompson, G. A. (1979). Membrane changes during growth of Tetrahymena in the presence of ethanol. Biochimica et biophysica acta 551, 315-327.

Navarro, J. M. \& Durand, G. (1978). Fermentation alcoolique: influence de la température sur l'accumulation d'alcool dans les cellules de levure. Annales de Microbiologie 129B, 215-224.
Panchal, P. J. \& Stewart, G. G. (1980). The effect of osmotic pressure on the production and excretion of ethanol and glycerol by a brewing yeast strain. Journal of the Institute of Brewing 86, 207-210.

Pasteur, L. (1879). Studies on Fermentation (translated by F. Faulkner). London: MacMillan.

Postgate, J. R. (1969). Viable counts and viability. Methods in Microbiology 1, 611-628.

Rose, A. H. (1980). Recent research on industrially important strains of Saccharomyces cerevisiae. In Biology and Activities of Yeasts, pp. 103-189. Edited by F. A. Skinner, S. M. Passmore \& R. R. Davenport. London: Academic Press.

Rose, A. H. \& Beavan, M. J. (1981). End-product tolerance and ethanol. In Trends in the Biology of Fermentations for Fuels and Chemicals, pp. 513531. Edited by A. Hollaender, R. Rabson, P. Rogers, A. San Pietro, R. Valentine \& R. Wolfe. New York: Plenum Press.

RothSTEIN, A. (1972). Ion transport in microorganisms. In Metabolic Pathways, vol. 6, pp. 17-39. Edited by L. E. Hopkin. New York: Academic Press.

Rothstein, A., Jennings, D. H., Demis, C. \& BRuce, M. (1959). The relationship of fermentation to cell structure in yeast. Biochemical Journal 71, 99-106.

Sols, A. \& MARCo, R. (1970). Concentrations of metabolites and binding sites. Implications in metabolic regulation. Current Topics in Cellular Regulation 2, 227-273.

Sols, A., Gancedo, C. \& de la Fuente, G. (1971). Energy-yielding metabolism in yeasts. In The Yeasts, vol. 2, pp. 271-307. Edited by A. H. Rose \& J. S. Harrison. London: Academic Press.

Thomas, D. S. \& Rose, A. H. (1979). Inhibitory effect of ethanol on growth and solute accumulation by Saccharomyces cerevisiae as affected by plasmamembrane lipid composition. Archives of Microbio$\log y$ 122, 49-55.

Thomas, D. S., Hossack, J. A. \& Rose, A. H. (1978). Plasma-membrane lipid composition and ethanol tolerance in Saccharomyces cerevisiae. Archives of Microbiology 117, 239-245.

WiCKerhaM, L. J. (1951). Taxonomy of yeasts. I. Techniques of classification. United States Department of Agriculture Technical Bulletin no. 1029. Washington, D.C.: U.S. Department of Agriculture. 